\title{
Pembangunan Laman Web EZ-Arabic Sebagai Alternatif Pembelajaran Maya Bahasa Arab bagi Pelajar Sekolah Rendah Malaysia
}

\author{
Mohd Firdaus Yahaya ${ }^{a *}$, Muhammad Sabri Sahrir ${ }^{b}$, Mohd Shahrizal Nasir ${ }^{a}$ \\ 'Jabatan Bahasa Arab, Fakulti Bahasa \& Komunikasi, Universiti Sultan Zainal Abidin \\ babatan Bahasa Arab \& Kesusasteraan, Kulliyyah IImu Wahyu \& Sains Kemanusiaan, Universiti Islam Antarabangsa Malaysia
}

*Corresponding author: mohdfirdaus@unisza.edu.my

\section{Article history}

Received :31 October 2012

Received in revised form :1 January 2013

Accepted : 15 February 2013

\begin{abstract}
The use of technology in teaching and learning is not a new phenomenon in the field of e-learning including its use for learning Arabic. This is evidenced through several research attempts and works done on learning through technology which is consistent with the existence of and access to a more effective, interesting and dynamic technology. Virtual learning, or also known as 'virtual learning environment' (VLE), is a teaching and learning platform that is designed to enhance students' learning experience through computer and internet. This article discusses the potential of a virtual learning platform towards learning Arabic through the development of EZ-Arabic as an alternative and interactive virtual platform for students to learn Arabic in primary schools. The design and development of EZ-Arabic prototype is using 'rapid prototyping' instructional design (ID) model which is proposed by Tripp and Bichelmeyer (1990) after conducting needs analysis of content and determining objectives. After the completion of the prototype development, a small-scale session of trying out with users was conducted through the social networking site Facebook ${ }^{\circledR}$ for two weeks from 15 February to 1 March 2012. Users' feedbacks and suggestions were compiled for it to be utilized in the next phase of installation and maintenance in designing the prototype. Qualitative findings were then collected that include 55 comments and suggestions from users with 48 'LIKES'. Qualitative findings of the proposed improvements and upgrades have been analyzed into seven (7) main themes that related to the web interface, application supports, challenges and distractions, material compatibility, usability, value-added and diversity, and content of syllabus.
\end{abstract}

Keywords: Learning Arabic language; instructional design; virtual learning; instructional technology; selfpaced learning

Abstrak

Penggunaan pembelajaran secara maya merupakan satu fenomena yang tidak asing lagi dalam dunia epembelajaran termasuklah bahasa Arab. Keadaan ini dapat dilihat menerusi beberapa usaha dan kajian yang dilakukan, selaras dengan kewujudan dan kemudahan teknologi yang lebih efektif, menarik dan bersifat dinamik. Pembelajaran secara maya atau dikenali juga dalam bahasa Inggeris sebagai 'virtual learning environment' (VLE) adalah satu platform pengajaran dan pembelajaran yang direka untuk meningkatkan pengalaman pembelajaran pelajar berbantukan komputer dan internet dalam proses tersebut. Artikel ini membincangkan potensi yang ada dalam platform pembelajaran secara maya dalam pembelajaran bahasa Arab dan mengaplikasikannya melalui pembangunan laman EZ-Arabic dibangunkan sebagai alternatif menarik dan interaktif bagi para pelajar dalam usaha mempelajari bahasa Arab secara maya khususnya bagi peringkat sekolah rendah. Proses pembinaan laman EZ-Arabic ini adalah berpandukan model reka bentuk pengajaran (instructional design-ID) 'rapid prototyping' yang dicadangkan oleh Tripp dan Bichelmeyer (1990) setelah menjalankan analisis keperluan isi kandungan dan penetapan objektif. Setelah proses pembangunan prototaip selesai, satu sesi penggunaan berskala kecil telah dijalankan selama 2 minggu bermula 15 Februari hingga 1 Mac 2012 menggunakan laman sosial Facebook $^{\circledR}$ bagi mengumpulkan maklum balas dan cadangan pengguna untuk digunakan dalam fasa berikutnya iaitu pemasangan dan penyelenggaraan prototaip ini. Dapatan kualitatif yang dikumpulkan ini telah mengumpulkan 55 komen dan cadangan berkaitan daripada pengguna dan 48 orang telah menekan butang 'LIKE'. Dapatan kualitatif berkaitan dengan cadangan penambahbaikan dan penaiktarafan ini telah dianalisis kepada tujuh (7) tema utama iaitu paparan antara muka, aplikasi sokongan, cabaran dan gangguan, kesesuaian bahan, kebolehgunaan, kepelbagaian nilai tambah dan kandungan sukatan pelajaran.

Kata kunci: Pembelajaran bahasa Arab; reka bentuk pengajaran; pembelajaran maya; teknologi pengajaran, pembelajaran kendiri 


\subsection{PENDAHULUAN}

Pemanfaatan teknologi dalam proses pengajaran dan pembelajaran $(\mathrm{P} \& \mathrm{P})$ merupakan satu keperluan pada hari ini. Situasi ini melibatkan proses $\mathrm{P} \& \mathrm{P}$ semua bidang termasuk bidang bahasa dan ia turut melibatkan semua peringkat pendidikan. Dewasa ini, penggunaan multimedia dalam P\&P merupakan antara kaedah yang banyak digunakan di semua peringkat pendidikan. Mayer (2001) mendefinisikan multimedia sebagai persembahan bahan pengajaran menggunakan perkataan dan gambar yang dapat menarik deria audio dan visual manusia. Pendapat yang dikemukakan oleh Mayer, kemudiannya dikembangkan oleh sarjana-sarjana lain dengan memasukkan elemen-elemen tambahan dalam multimedia seperti penambahan elemen suara dalam penerokaan pengajaran bahasa (Bush, 2007), pemanfaatan jaringan internet melalui World Wide Web (WWW) (Joliffe, Ritter \& Stevens, 2001), dan pemanfaatan grafik yang menarik dalam pengajaran kosa kata bahasa (Salsbury, 2006; Bush, 2007). Selain itu, variasi pemanfaatan teknologi dalam P\&P bahasa semakin bertambah dengan munculnya bahan-bahan elektronik seperti buku elektronik (e-buku), video digital, ujian mendengar secara interaktif, bahan bacaan atas talian dan komuniti maya (Gill, 2006). Merujuk kepada perkembangan positif perkembangan teknologi dan manfaatnya dalam $\mathrm{P} \& \mathrm{P}$ pendidikan bahasa, maka ia dilihat amat wajar untuk dimanfaatkan dalam P\&P bahasa Arab khususnya yang melibatkan pelajar bukan penutur jati. Bahan pengajaran yang menarik dan bersifat interaktif akan dapat menarik minat dan motivasi pelajar untuk mempelajari bahasa al-Quran ini.

\subsection{PENGGUNAAN MULTIMEDIA DALAM P\&P BAHASA ARAB}

Dewasa ini, pemanfaatan unsur teknologi dalam pendidikan khususnya yang melibatkan multimedia dalam bahasa Arab sedang berkembang secara positif walaupun masih pada tahap yang rendah dan terhad. Penggunaan multimedia dalam P\&P bahasa Arab didapati lebih mengikut trend semasa dalam penggunaan bahan teknologi berbanding mencipta inovasi yang boleh dimanfaatkan oleh pengguna dalam bidang ini (Mohd Feham, 2006). Selain itu, kajian terhadap beberapa buah sekolah menengah agama di Malaysia juga mendapati bahawa penggunaan teknologi dalam P\&P bahasa Arab di dalam kelas adalah masih amat terhad (Zawawi, 2008). Keadaan ini antaranya disebabkan oleh beberapa faktor seperti situasi guru yang masih memilih kaedah tradisional dalam proses $\mathrm{P} \& \mathrm{P}$ berbanding kaedah moden yang memanfaatkan teknologi, di samping faktor kekurangan masa dan usaha untuk menyediakan bahan berbentuk multimedia sebelum sesi P\&P berlangsung (Zawawi, 2008). Tahap pengetahuan dan kemahiran menggunakan komputer yang rendah di kalangan guru bahasa Arab juga turut menyebabkan proses pemanfaatan multimedia menjadi terhad dalam P\&P bahasa Arab (Zawawi, 2008; Mohd Feham \& Isarji, 2000). Selain itu, kekurangan latihan atau bengkel berkaitan kemahiran menggunakan komputer turut menjadi punca kekangan perkembangan pemanfaatan teknologi dalam P\&P bahasa Arab di Malaysia (Ashinida, Afendi \& Mohd Shabri, 2004).

3.0 KEPERLUAN MEMANFAATKAN PEMBELAJARAN MAYA DALAM P\&P BAHASA ARAB DI SEKOLAH RENDAH

Situasi semasa P\&P bahasa Arab di Malaysia didapati masih kurang memanfaatkan kemudahan teknologi atas beberapa kekangan yang telah disebutkan sebelum ini. Ini semua memerlukan kepada usaha perubahan ke arah yang lebih baik di semua peringkat. Daripada beberapa kajian yang dilakukan, masalah atau kekangan dalam pemanfaatan teknologi dalam P\&P merujuk kepada situasi guru dan pelajar, bukan kemudahan sumber teknologi (Zawawi, 2008; Mohd Feham \& Isarji, 2000; Ashinida, Afendi \& Mohd Shabri, 2004). Jika disoroti sejarah perkembangan pendidikan di Malaysia dan kaitannya dengan alat bantu mengajar berorientasikan teknologi, kesemua prasarana yang disediakan adalah pada tahap yang amat baik dan mengikut arus peredaran zaman sejak awal tahun 50-an lagi seperti alat teknologi pendidikan (ATP) telah digunakan dalam P\&P sekolahsekolah di Malaysia, meskipun penggunaannya didapati masih terhad (Abd. Rahman, 2000). Bidang teknologi pengajaran dan pembelajaran berbantukan komputer telah berkembang dengan pesat dan dikenali dengan pelbagai istilah seperti EPembelajaran/E-Learning, Latihan Berasaskan Komputer/Computer-Based Training (CBT), Latihan Berasaskan Internet/Internet-Based Training (IBT), Latihan Berasaskan Web/Web-Based Training (WBT) dan Pembelajaran Bahasa Berbantukan Komputer/Computer-Assisted Language Learning (CALL) (Mohd Feham, 2006). Di sebalik istilah-istilah ini, muncul pula teknologi pembelajaran maya (virtual learning) sebagai salah satu platform yang membolehkan pelajar untuk melihat persekitaran pembelajaran, menilai situasi dan prestasi, melakukan tindakan susulan dan meneruskan pembelajaran mereka dengan lebih baik. Ini semua didapati melalui pengalaman pelajar yang melalui proses pembelajaran yang sama dalam keadaan yang sama berulang (Pimentel, 1999).

Keperluan pemanfaatan teknologi dalam P\&P juga dilihat sebagai satu keperluan bagi para pelajar bahasa Arab terutama di peringkat sekolah rendah. Pengenalan program j-QAF iaitu singkatan kepada Jawi, al-Quran, Arab dan Fardu Ain bagi semua pelajar peringkat rendah menjadi antara faktor pendesak (push factor) kepada usaha pemanfaatan bahan bantu mengajar berasaskan teknologi. Dengan usaha seperti ini beberapa kekangan dalam proses $\mathrm{P} \& \mathrm{P}$ bahasa Arab dapat diatasi secara berperingkat. Namun begitu, perubahan ke arah situasi lebih baik ini memerlukan usaha dan semangat yang positif daripada kalangan guru. Hal ini merupakan antara perkara yang ditegaskan oleh Siti Fatimah dan Ab. Halim (2010) dalam kajian mereka berkaitan persepsi guru terhadap penggunaan alat bantu mengajar berasaskan teknologi multimedia dalam pengajaran j-QAF. Dalam konteks pengajaran dan pembelajaran bahasa Arab peringkat rendah, terdapat beberapa perkara yang perlu diambil perhatian serius sebagai usaha untuk memastikan para pelajar bahasa Arab daripada kalangan bukan penutur jati menjalani proses pembelajaran yang berkesan, antaranya:

a) Tahap motivasi yang perlu sentiasa dipupuk oleh guru dan keadaan sekeliling kerana motivasi diperlukan dalam usaha pelajar mempelajari bahasa kedua hasil daripada keperluan dan keinginan untuk mempelajarinya (Ellis, 1994).

b) Persembahan bahan pengajaran yang menarik turut menjadi antara perkara penting dalam pengajaran dan pembelajaran bahasa Arab khususnya di peringkat rendah. Pemanfaatan teknologi dalam bahan $\mathrm{P} \& \mathrm{P}$ dilihat sebagai satu inovasi pendidikan yang dapat menarik lebih tinggi minat pelajar terhadap pelajaran bahasa Arab. Sebagai contoh aplikasi permainan kosa kata bahasa Arab secara atas talian sepertimana yang dijalankan oleh Muhammad Sabri dan Ghazali (2012).

c) Sumber rujukan utama dan tambahan bagi subjek bahasa Arab perlu diletakkan dalam satu medium khas bagi memudahkan pelajar mengakses secara mudah dan cepat. Keterikatan pelajar dengan buku teks semata-mata akan 
menjadikan proses pengajaran dan pembelajaran menjadi pasif dan kekurangan motivasi. Perkara ini dijelaskan oleh Gardner (1985) apabila mentakrifkan motivasi pembelajaran bahasa menurut sebagai satu tahap di mana seseorang bekerja dan berusaha untuk mempelajari bahasa kerana keinginannya untuk melakukan demikian dan pengalaman merasakan kepuasan ketika menjalankan aktiviti tersebut.

\subsection{PERMASALAHAN DAN OBJEKTIF KAJIAN}

Pemanfaatan teknologi dalam $\mathrm{P} \& \mathrm{P}$ turut membuka ruang kepada pelajar untuk memahami dan mengulangkaji pelajaran secara kendiri seperti yang dijelaskan oleh Bruner (1996) ketika membicarakan sistem pembelajaran masa kini yang lebih terbuka dan menggalakkan pencarian ilmu pengetahuan secara terbimbing. Secara ringkasnya, objektif kajian yang dijalankan ini adalah mengkaji beberapa persoalan seperti berikut:

a) Mengkaji tahap penggunaan multimedia dalam bahasa Arab dan mengaplikasikannya dalam teknologi pembelajaran maya di kalangan pelajar di peringkat sekolah rendah

b) Membina dan mereka-bentuk sebuah prototaip pembelajaran bahasa Arab berasaskan platform pembelajaran maya yang dikenali dengan EZ-Arabic.

c) Mengumpul dan menilai komen dan maklum balas pengguna terhadap prototaip EZ-Arabic dengan menggunakan laman sembang sosial Facebook ${ }^{\circledR}$ bagi tujuan pemenambahbaikan.

15.0 METODOLOGI KAJIAN DAN MODEL REKA BENTUK INSTRUKSIONAL YANG DIGUNAKAN

Proses pembinaan laman EZ-Arabic ini adalah berpandukan model reka bentuk pengajaran (instructional design -ID) 'rapid prototyping' yang dicadangkan oleh Tripp dan Bichelmeyer (1990) seperti yang tertera dalam rajah 1.0 di bawah:

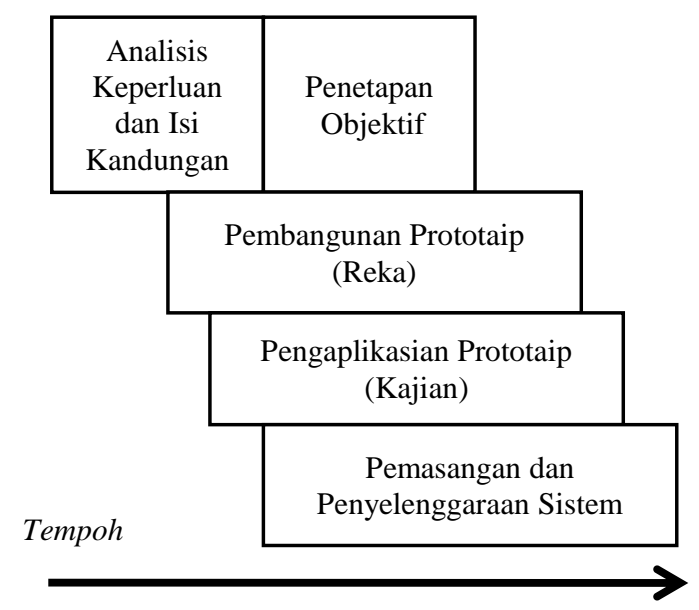

Rajah 1.0 Model Rapid Prototyping (Tripp, S. \& Bichelmeyer, B. (1990))

Proses reka bentuk prototaip dijalankan berdasrkan analisis keperluan isi kandungan dan penetapan objektif. Setelah proses pembangunan prototaip selesai, satu sesi penggunaan berskala kecil telah dijalankan selama 2 minggu bermula 15 Februari hingga 1 Mac 2012 menggunakan laman sosial Facebook ${ }^{\circledR}$ bagi mengumpulkan maklum balas dan cadangan pengguna untuk digunakan dalam fasa berikutnya iaitu pemasangan dan penyelenggaraan prototaip ini. Dapatan kualitatif yang dikumpulkan ini telah mengumpulkan 55 komen dan cadangan berkaitan daripada pengguna dan 48 orang telah menekan butang 'LIKE'.

Pembangunan prototaip EZ-Arabic adalah untuk membantu proses pembelajaran berterusan di luar bilik darjah secara maya iaitu melalui laman web. Pembelajaran secara maya ini memfokuskan pelajar-pelajar dari tahun satu sehingga tahun 6 di peringkat sekolah rendah, di samping menjadi bahan rujukan pembelajaran sampingan bagi para pelajar selain daripada buku teks yang telah disediakan oleh Kementerian Pelajaran Malaysia. Prototaip EZ-Arabic ini disokong oleh pelbagai jenis fail multimedia, teks, audio dan visual seperti PDF, gambar, MP3, video dan permainan digital. Fasa dan proses pembangunan dan rekab entuk laman prototaip EZ-Arabic berasaskan model 'rapid prototyping' oleh Tripp dan Bichelmeyer (1990) adalah seperti yang ditunjukkan dalam jadual 1.0:

Jadual 1.0 Fasa dan proses reka bentuk dan pembangunan laman prototaip EZ-Arabic

\begin{tabular}{|c|c|}
\hline Fasa & Proses \\
\hline $\begin{array}{l}\text { Analisis Keperluan } \\
\text { dan Isi Kandungan }\end{array}$ & $\begin{array}{l}\text { Analisis keperluan pelajar } \\
\text { Analisis keperluan institusi } \\
\text { Analisis isi kandungan pembelajaran } \\
\text { Analisis e-pembelajaran yang sedia ada }\end{array}$ \\
\hline $\begin{array}{l}\text { Penetapan } \\
\text { Objektif }\end{array}$ & $\begin{array}{l}\text { Objektif pembelajaran bahasa } \\
\text { Objektif kemahiran berbahasa } \\
\text { Reka bentuk asas }\end{array}$ \\
\hline $\begin{array}{l}\text { Pembangunan } \\
\text { Prototaip }\end{array}$ & $\begin{array}{l}\text { Kerja berpasukan } \\
\text { Menggunakan pelbagai sumber kajian } \\
\text { tentang teknologi }\end{array}$ \\
\hline $\begin{array}{l}\text { Pengaplikasian } \\
\text { Prototaip }\end{array}$ & $\begin{array}{l}\text { Mengadakan sesi penggunaan } \\
\text { percubaan secara dalam skala yang } \\
\text { kecil. } \\
\text { Sesi penggunaan dikendalikan melalui } \\
\text { Facebook } \\
\text { Mengumpul maklumat dan maklum } \\
\text { balas daripada pengguna }\end{array}$ \\
\hline $\begin{array}{l}\text { Pemasangan dan } \\
\text { Penyelenggaraan } \\
\text { Sistem }\end{array}$ & $\begin{array}{l}\text { Mengkaji semula maklumat dan } \\
\text { maklum balas yang diterima daripada } \\
\text { pengguna } \\
\text { Mengkaji semula proses reka bentuk } \\
\text { dan pembangunan prototaip } \\
\text { Penambahbaikan secara berterusan }\end{array}$ \\
\hline
\end{tabular}

6.0 PEMBANGUNAN REKA BENTUK PROTOTAIP EZ$A R A B I C$ DAN KOMPONEN-KOMPONENNYA

Prototaip EZ-Arabic telah dibangunkan dengan menggunakan sistem kod HyperText Markup Language (HTML) dengan sokongan kod Hypertext Preprocessor (PHP). Platform ini dibangunkan menggunakan platform Linux. Manakala alamat untuk mengakses ke laman prototaip EZ-Arabic adalah http://ezarabic.net/v1. Pembinaan laman EZ-Arabic ini adalah dengan menggunakan model rapid prototyping (Tripp dan Bichelmeyer, 1990) bagi proses rekaan dan pembangunan perisian bagi tujuan pendidikan. Komen dan cadangan untuk 
penambahbaikan sepanjang proses pembangunan prototaip EZArabic ini telah dijalankan dengan menggunakan laman sosial Facebook $^{\circledR}$ dijalankan selama 2 minggu bermula 15 Februari hingga 1 Mac 2012.

Prototaip EZ-Arabic ini dilengkapi oleh beberapa komponen untuk membantu proses pembelajaran bahasa Arab. Bahan kandungan yang terdapat dalam prototaip EZ-Arabic adalah hasil daripada gabungan buku teks bahasa Arab sukatan pelajaran Bahasa Arab Kurikulum Standard Sekolah Rendah (KSSR) yang disediakan Kementerian Pelajaran Malaysia dan juga sumber terbuka antaranya adalah seperti laman YouTube ${ }^{\mathrm{TM}}$, perkhidmatan terjemahan Google ${ }^{\mathrm{TM}}$ dan Cbox serta permainan-permainan asas dalam mempelajari bahasa Arab. Terdapat lapan komponen utama dalam prototaip EZ-Arabic iaitu: (1) E-Buku, (2) Video, (3) Laman Sesawang, (4) Audio, (5) Permainan, (6) Sembang, (7) Papan Kekunci Arab dan (8) Hubungi Kami yang disenaraikan dengan terperinci seperti berikut:

\subsection{E-Buku (Rajah 2.0)}

Laman prototaip EZ-Arabic menggunakan buku bahasa Arab sukatan Kementerian Pelajaran Malaysia peringkat sekolah rendah. Kemudian pembahagian dilakukan mengikut tahun atau tahap pembelajaran iaitu dari tahun satu sehingga tahun enam. Selain daripada pembahagian mengikut tahun, e-buku dalam prototaip EZ-Arabic ini juga telah dibahagikan kepada empat subbahagian utama. Pembahagian-pembahagian tersebut adalah seperti berikut: (a) Bacaan (Qiraah), (b) Percakapan (Kalam), (c) Perbualan (Hiwar) dan (d) Nasyid.

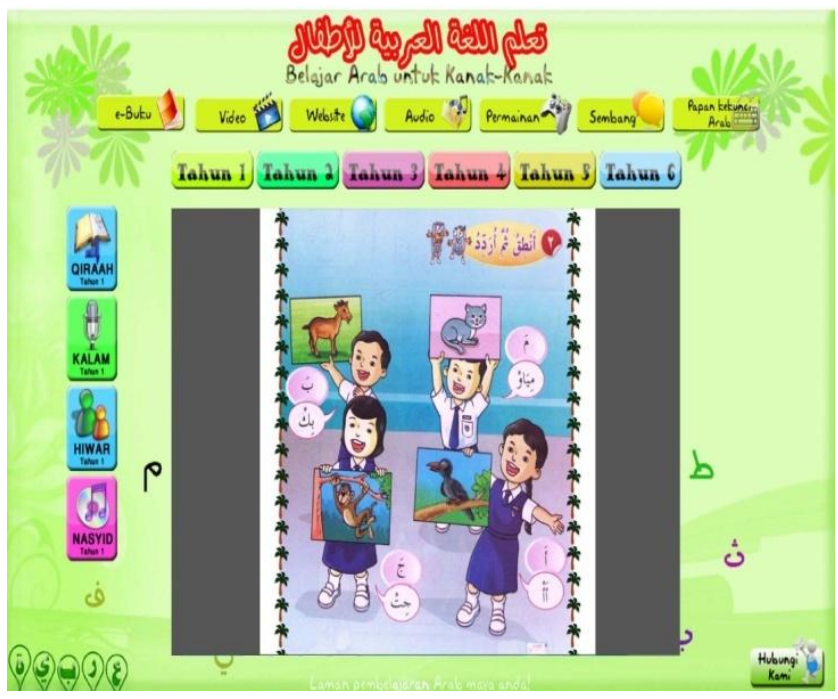

Rajah 2.0 Paparan komponen e-buku dalam prototaip EZ-Arabic

\subsection{Video (Rajah 3.0)}

Video adalah komponen kedua yang terdapat dalam prototaip EZArabic. Komponen video dibahagikan kepada lima bahagian utama. Pembahagian-pembahagian tersebut adalah seperti berikut: (a) Huruf, (b) Kosa Kata, (c) Nasyid, (d) Muslim Kids dan (e) Kartun. Semua video yang terdapat dalam komponen ini diperoleh daripada sumber terbuka iaitu YouTube ${ }^{\mathrm{TM}}$. Bahagian pertama daripada komponen video adalah huruf. Pada bahagian ini, EZArabic memfokuskan kepada cara sebutan huruf hija'iyyah yang terdapat dalam bahasa Arab dalam bentuk persembahan yang pelbagai. Ia bermula dari cara sebutan setiap huruf sehinggalah cara sebutan huruf dalam perkataan berbentuk irama dan lagu.
Bahagian kedua dalam komponen ini pula menekankan pada perbendaharaan kata bahasa Arab. Terdapat berbagai-bagai jenis tema yang dimuatkan pada bahagian ini. Contohnya adalah kelas, nama binatang dan buah-buahan. Nasyid adalah bahagian ketiga dalam komponen ini. Ia memuatkan lapan buah nasyid pembelajaran bahasa Arab untuk peringkat rendah. Muslim Kids adalah bahagian yang seterusnya dalam komponen ini yang terkandung di dalamnya sebanyak lapan buah lagu. Bahagian yang terakhir dalam komponen ini adalah kartun. Terdapat pada bahagian ini kartun-kartun versi kanak-kanak. Salah satu daripada kartun-kartun yang terdapat pada bahagian ini adalah kartun Upin dan Ipin. Ia telah dirakamkan semula dan diterjemahkan ke dalam bahasa Arab. Selain daripada itu, terdapat juga kartun yang disediakan sari kata pada video tersebut.

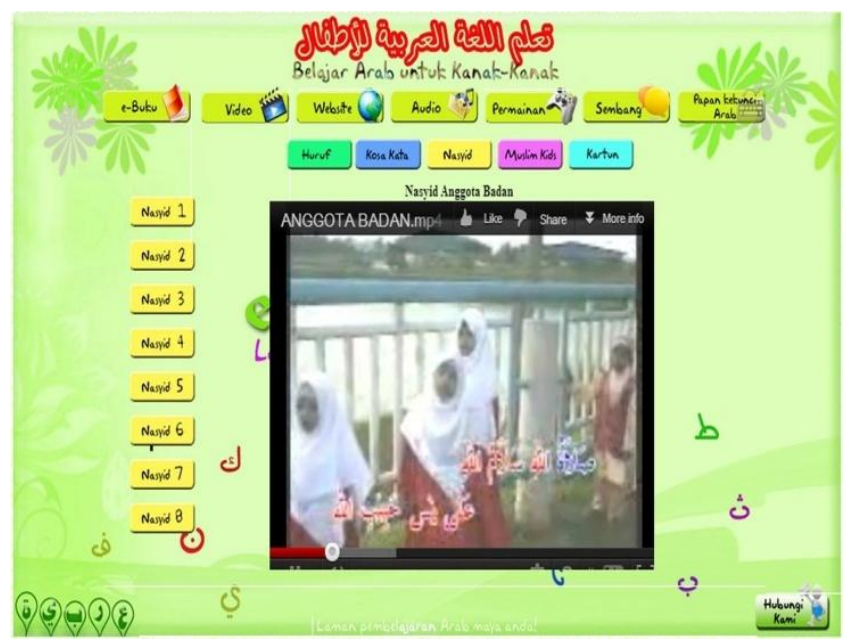

Rajah 3.0 Paparan komponen video dalam prototaip EZ-Arabic

\subsection{Laman Sesawang (Rajah 4.0)}

Sistem kod iframe dalam HTML dimanfaatkan dalam pembangunan laman prototaip EZ-Arabic. Dengan menggunakan kod tersebut, para pelajar boleh mengakses laman sesawang lain yang telah ditetapkan dalam laman prototaip ini sebagai contoh laman Tanzil.net, kamus serta terjemahan Google ${ }^{\mathrm{TM}}$. Terdapat tujuh bahagian utama telah dipilih untuk diletakkan dalam komponen ini. Bahagian pertama dalam komponen ini adalah alQuran. Bahagian kedua dalam komponen ini adalah kamus. Ia terbahagi kepada dua jenis; kamus bergambar dan kamus tanpa gambar. Bahagian terjemahan dalam komponen ini pula dimanfaatkan daripada perkhidmatan terjemahan yang disediakan oleh Google ${ }^{\mathrm{TM}}$. Bagi membantu para pelajar untuk membaca teks Arab yang tidak mempunyai sistem tashkil (baris atau tanda bunyi; fathah, kasrah, dommah), maka laman ini menyediakan perkhidmatan tersebut bagi memudahkan pembacaan dalam bahasa Arab. Bahagian seterusnya dalam komponen ini adalah pautan ke laman pembelajaran bahasa Arab. Perkhidmatan ini disediakan secara percuma dan terdapat juga yang berbayar. Sebagai contoh laman perkhidmatan pembelajaran bahasa Arab secara maya adalah seperti: MadinahArabic.com, ArabAcademy.com dan MyStormKids.com. 


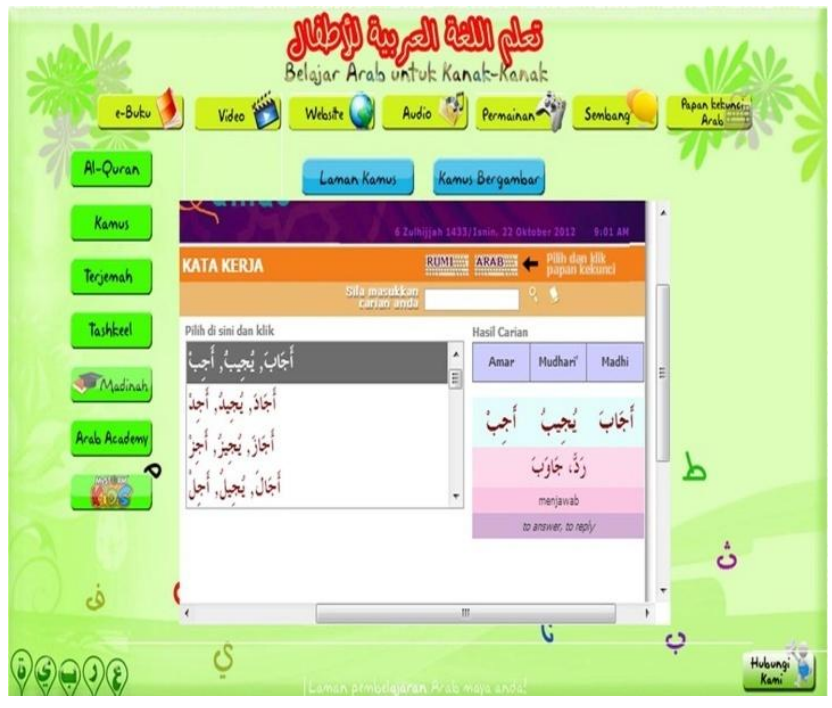

Rajah 4.0 Paparan komponen Website dalam prototaip EZ-Arabic

\subsection{Audio (Rajah 5.0 Dan Rajah 6.0)}

Komponen keempat dalam laman prototaip EZ-Arabic adalah audio. Komponen ini terbahagi kepada tiga bahagian. Bahagian pertama daripada komponen ini adalah album nasyid "Ustaz Mior" yang digunakan dalam sukatan pelajaran bahasa Arab peringkat sekolah rendah. Setiap lagu daripada album ini disertakan lirik. Dua bahagian lagi adalah nasyid daripada kumpulan Dhuha dan MyStormKids yang dimanfaatkan dari laman YouTube ${ }^{\mathrm{TM}}$.

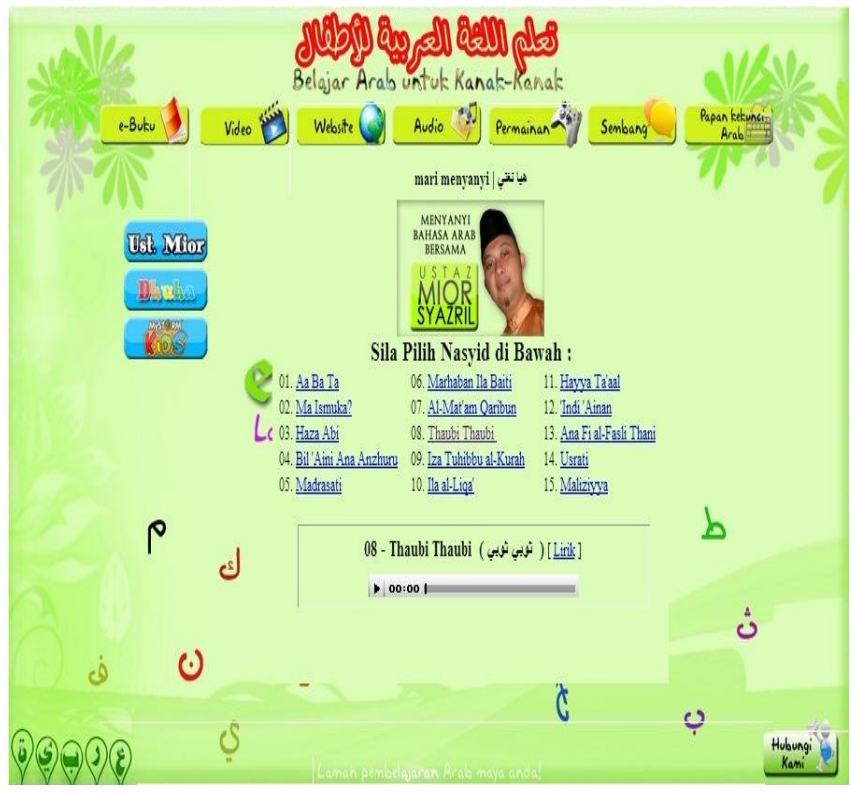

Rajah 5.0 Paparan komponen audio dalam prototaip EZ-Arabic

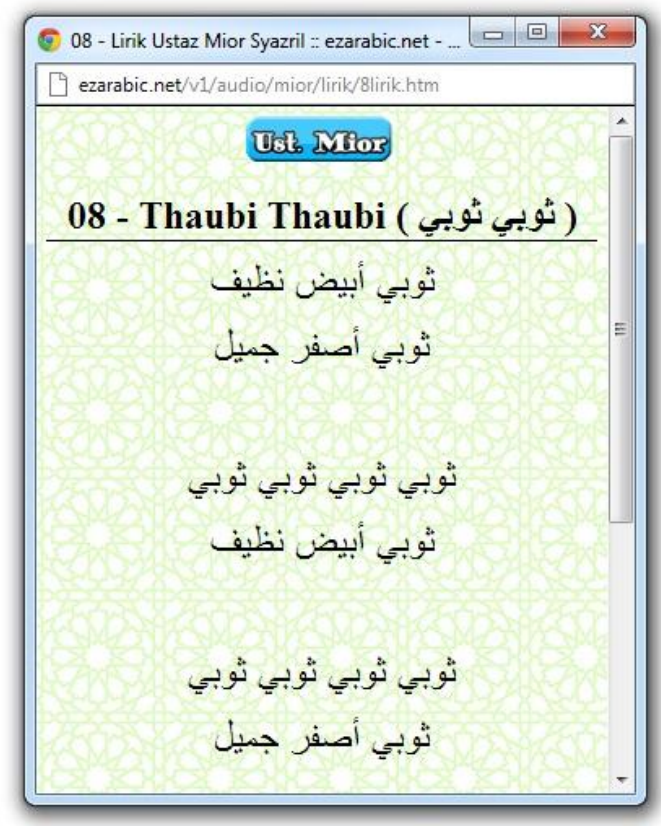

Rajah 6.0 Paparan lirik dalam prototaip EZ-Arabic

\subsection{Permainan (Rajah 7.0)}

Komponen permainan bahasa juga diletakkan bersama dalam laman prototaip EZ-Arabic. Komponen ini ditambah untuk menambah aktiviti berbahasa di kalangan pelajar. Terdapat sembilan jenis permainan bahasa yang telah disediakan dalam laman prototaip ini meliputi permainan penentuan huruf, kosa kata, susun ayat, ungkapan, jam dan who wants to be a millionaire $^{\circledR}$

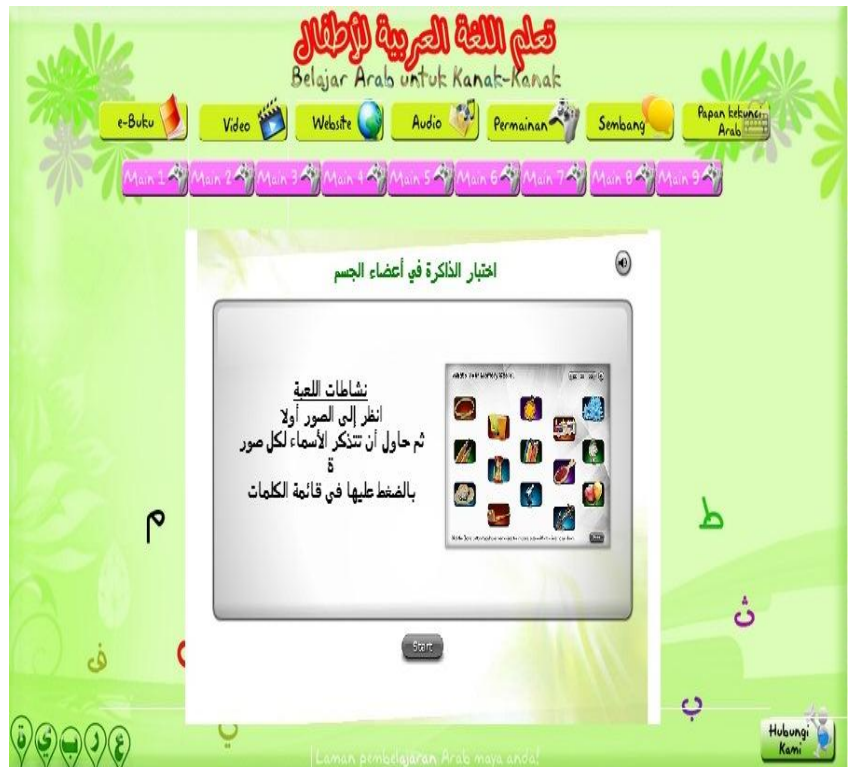

Gambar 7.0 Paparan komponen permainan dalam prototaip EZ-Arabic 


\subsection{Ruangan Sembang (Rajah 8.0)}

Laman prototaip EZ-Arabic juga telah menyediakan komponen "ruangan sembang". Penambahan komponen ini dilakukan bagi memberi ruang kepada para pengguna laman EZ-Arabic untuk berkomunikasi antara satu dengan yang lain secara langsung. Ruangan ini juga boleh dimanfaatkan oleh pengguna dengan perkongsian pendapat tentang penggunaan laman prototaip EZArabic ini dengan pengguna-pengguna lain.

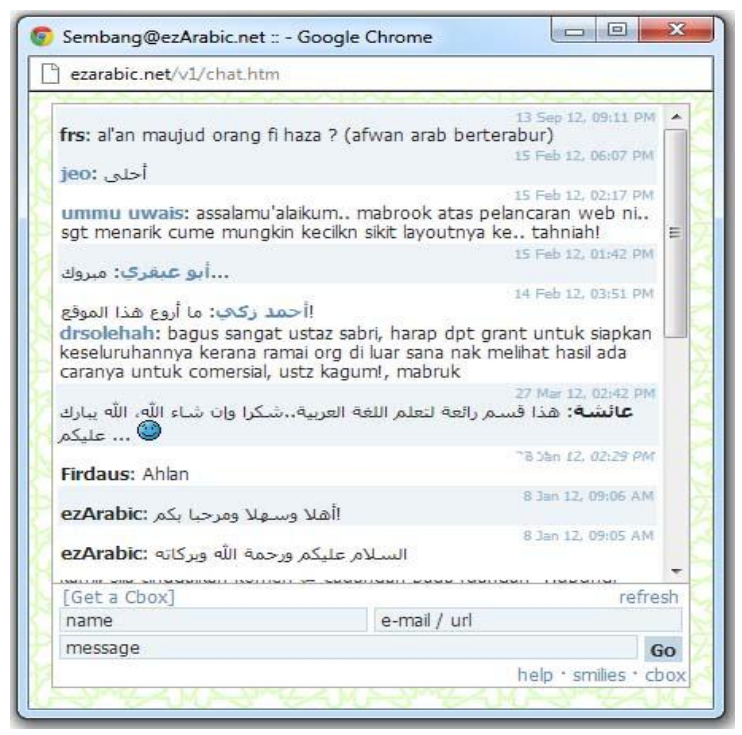

Gambar 8.0 Paparan ruangan sembang dalam prototaip EZ-Arabic

\subsection{Papan Kekunci Arab (Rajah 9.0)}

Komponen papan kekunci askara Arab juga ditambah bagi memudahkan pelajar untuk menaip askara-askara dalam bahasa Arab di laman EZ-Arabic. Penggunaan papan kekunci ini tidak terhad untuk digunakan pada laman ini sahaja, malah ia boleh digunakan pada laman-laman lain. Selain itu, sistem tashkil (baris) juga disediakan dalam fungsi papan kekunci ini.

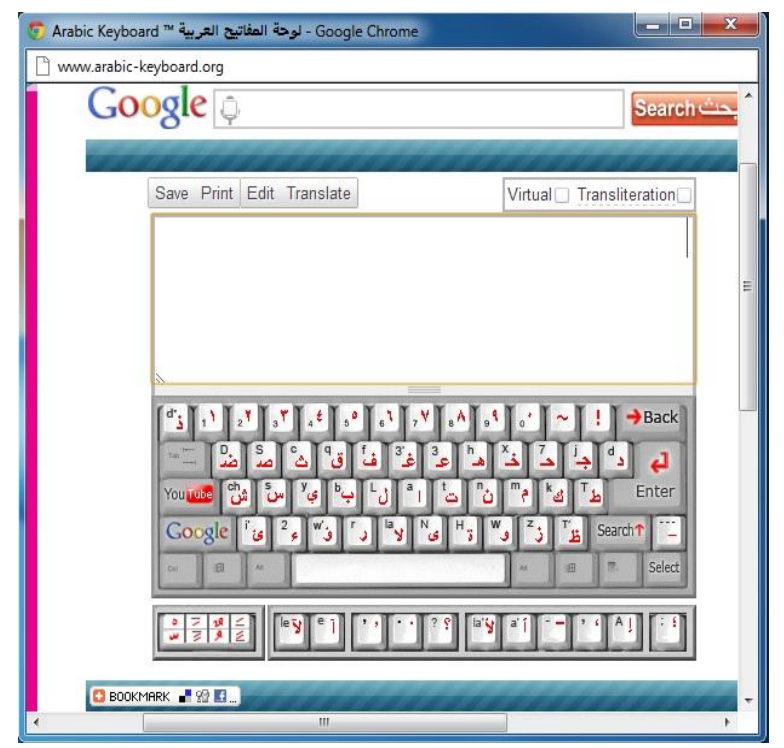

Gambar 9.0 Paparan papan kekunci atas talian yang digunakan dalam prototaip EZ-Arabic

\subsection{Hubungi Kami (Rajah 10.0):}

Komponen terakhir dalam prototaip EZ-Arabic ini adalah hubungi kami. Komponen ini membuka ruang kepada para pelajar serta pengguna lain untuk memberi komen, melontarkan idea serta cadangan tentang pengalaman dan pengamatan mereka sepanjang penggunaan laman EZ-Arabic ini sebagai bahan bantu pembelajaran sampingan pada peringkat rendah.

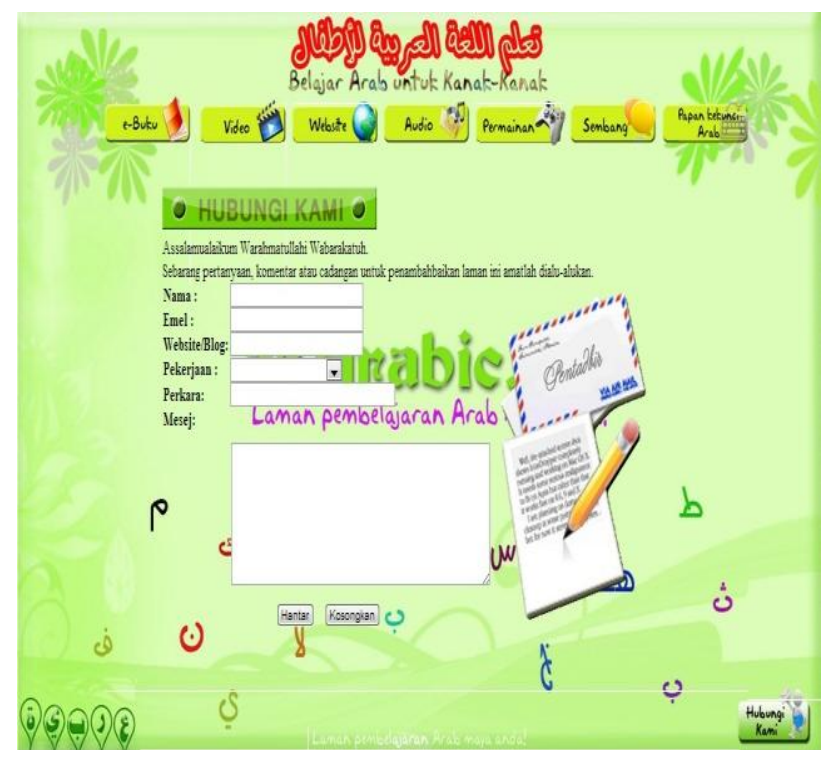

Gambar 10.0 Paparan komponen hubungi kami dalam prototaip EZArabic

\subsection{DAPATAN DAN HASIL KAJIAN}

Bagi mengkaji komen dan maklum balas pengguna bagi menjalankan proses penambahbaikan terhadap laman EZ-Arabic, satu kaji selidik telah diadakan bagi mengumpul komen dan cadangan daripada para pengguna laman ini. Kaji selidik dijalankan menggunakan Facebook ${ }^{\circledR}$ berdasarkan fakta yang menunjukkan bahawa Facebook ${ }^{\circledR}$ merupakan medium popular yang digunakan secara meluas dalam dunia maya (Ellison, Steinfield \& Lampe, 2007; Sharifah Sofia, Siti Zobidah, Jusang Bolong \& Mohd Nizam, 2011). Kaji selidik secara atas talian ini telah bermula pada 15 Februari 2012 sehingga komen terakhir yang diterima pada 1 Mac 2012, iaitu dalam tempoh 2 minggu. Selain itu, kesemua komen dan cadangan yang diberikan oleh pengguna EZ-Arabic dapat dibaca oleh orang umum dan disimpan untuk tujuan rekod dan analisis. Sebanyak 55 komen berkaitan laman EZ-Arabic telah diterima dan sebanyak 48 pengguna telah menekan butang LIKE sebagai tanda setuju dan berpartisipasi dalam kaji selidik ini. Rajah 11.0 berikut adalah paparan kaji selidik yang dijalankan melalui aplikasi Facebook ${ }^{\circledR}$. 


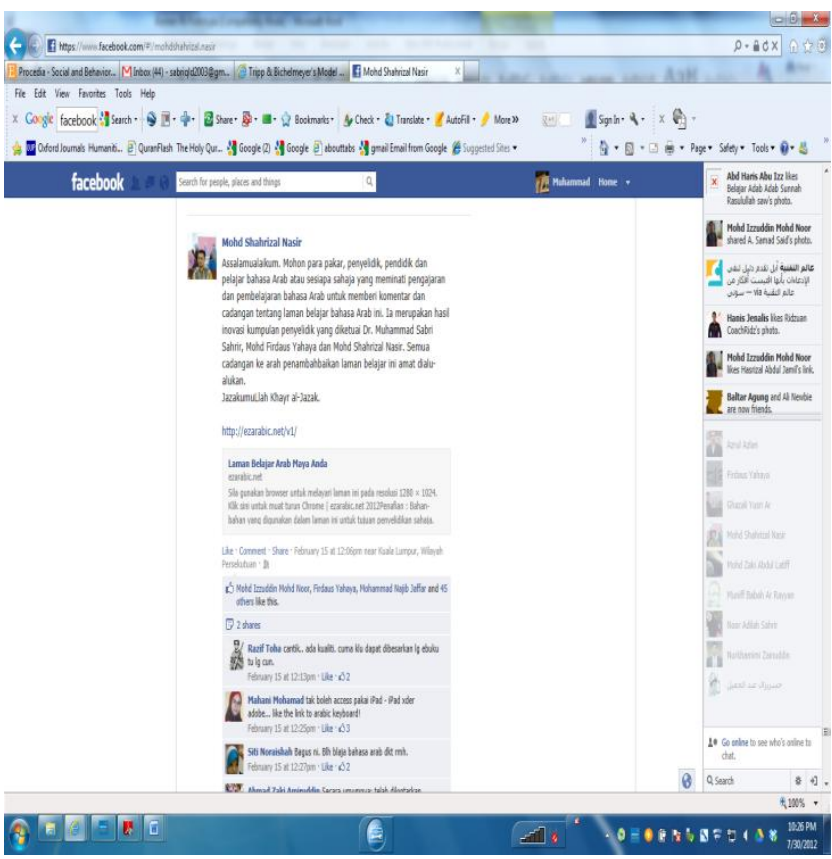

Rajah 11.0 Soal selidik mengenai penggunaan prototaip EZ-Arabic atas talian

Kaji selidik ini dijalankan dalam bahasa Melayu memandangkan sasaran utama pengguna EZ-Arabic adalah para pelajar Melayu yang mengikuti program j-QAF di sekolahsekolah rendah seluruh Malaysia. Berikut adalah kutipan soalan kaji selidik bagi tujuan mendapatkan komen dan cadangan penambahbaikan laman EZ-Arabic:

"Assalamualaikum. Mohon para pakar, penyelidik, pendidik dan pelajar bahasa Arab atau sesiapa sahaja yang meminati pengajaran dan pembelajaran bahasa Arab untuk memberi komentar dan cadangan tentang laman belajar bahasa Arab ini. Ia merupakan hasil inovasi kumpulan penyelidik yang diketuai Dr. Muhammad Sabri Sahrir, Mohd Firdaus Yahaya dan Mohd Shahrizal Nasir. Semua cadangan ke arah penambahbaikan laman belajar ini amat dialu-alukan. JazakumuLlah Khayr al-Jazak. LINK : http://ezarabic.net/v1/".

Berdasarkan maklum balas yang diterima, berikut dinyatakan komen dan cadangan daripada soalan kaji selidik mengikut tematema utama selepas dianalisis. Kesemua komen dan cadangan ini akan digunakan dalam usaha penambahbaikan laman prototaip EZ-Arabic sebagai satu medium pembalajaran bahasa Arab secara atas talian. Jadual 2.0 berikut memaparkan komen dan cadangan para pengguna EZ-Arabic yang telah dianalisis kepada tujuh tema-tema utama seperti berikut:

Hasil dapatan daripada kaji selidik menunjukkan bahawa para pengguna EZ-Arabic telah memberi respons yang amat positif dalam usaha penambahbaikan laman prototaip ini. Hal ini secara tidak langsung menunjukkan potensi laman ini bagi mendapat sambutan yang baik daripada para pengguna yang bukan sahaja terdiri daripada para guru bahasa Arab dan pelajar bahasa Arab di peringkat sekolah rendah, malah turut dimanfaatkan oleh para ibu bapa para pelajar. Kesemua komen dan cadangan ini akan dimanfaatkan secara holistik bagi penghasilan laman EZ-Arabic yang lebih sempurna pada masa akan datang.
Jadual 2.0 Tema utama bagi komentar dan cadangan pengguna EZArabic

\begin{tabular}{|c|c|}
\hline No. & Komentar \& Cadangan \\
\hline 1 & $\begin{array}{l}\text { PAPARAN ANTARA MUKA } \\
\text { - Penambahbaikan paparan antara muka yang lebih mesra } \\
\text { pengguna. } \\
\text { - Pembesaran buku elektronik (e-buku) supaya lebih jelas. } \\
\text { - Penggunaan dwibahasa pada arahan. } \\
\text { - Peletakan butang "hubungi kami" pada bahagian atas } \\
\text { laman. } \\
\text { - Penambahbaikan persembahan paparan antara muka agar } \\
\text { kelihatan lebih menarik dan unik. } \\
\text { - Penambahan unsur warna yang bersesuaian dengan } \\
\text { pengguna kanak-kanak. }\end{array}$ \\
\hline 2 & $\begin{array}{l}\text { APLIKASI SOKONGAN } \\
\text { - Penambahbaikan pada sebahagian audio dan video. } \\
\text { - Penambahan audio dalam bahagian e-buku. } \\
\text { - Penambahan maklumat berkenaan tatacara pemasangan } \\
\text { kemudahan penulisan askara Arab dalam Windows }{ }^{\circledR} \text {. } \\
\text { - Penambahan perisian e-Jawi. } \\
\text { - Cadangan mempelbagaikan pautan tambahan berkaitan } \\
\text { pembelajaran bahasa Arab seperti kamus elektronik. }\end{array}$ \\
\hline 3 & $\begin{array}{l}\text { CABARAN DAN GANGGUAN } \\
\text { - Terdapat gangguan seperti iklan yang tidak sesuai daripada } \\
\text { pemanfaatan laman YouTube }{ }^{\mathrm{TM}} \text {. } \\
\text { - Penghasilan video sendiri dan dimuat naik dalam laman } \\
\text { YouTube }{ }^{\mathrm{TM}} \text { untuk manfaat orang ramai. } \\
\text { - Terdapat beberapa paparan yang tidak dapat diakses. }\end{array}$ \\
\hline 4 & $\begin{array}{l}\text { KESESUAIAN BAHAN } \\
\text { - Mudah untuk diakses dan bersesuaian dengan peringkat } \\
\text { kanak-kanak. } \\
\text { - Penggunaan video yang menggunakan bahasa Arab tinggi } \\
\text { (standard Arabic) dan bukan bahasa dialek. } \\
\text { - Sebahagian ilustrasi yang menggunakan askara Arab perlu } \\
\text { diperbetulkan. } \\
\text { - Penggunaan dwibahasa bagi arahan pada butang dalam } \\
\text { laman ini. }\end{array}$ \\
\hline 5 & $\begin{array}{l}\text { KEBOLEHGUNAAN } \\
\text { - Boleh digunakan dalam pembelajaran di rumah. } \\
\text { - Kepelbagaian sumber maklumat berkaitan sukatan } \\
\text { pelajaran. } \\
\text { - Bersesuaian untuk pelajar pada peringkat umur rendah. }\end{array}$ \\
\hline 6 & $\begin{array}{l}\text { KEPELBAGAIAN NILAI TAMBAH } \\
\text { - Keperluan untuk terus dibangunkan dalam perisian iPad. } \\
\text { - Boleh dibangunkan menurut keperluan pengguna peringkat } \\
\text { tinggi. } \\
\text { - Keperluan kamus elektronik bergambar. } \\
\text { - Keperluan menyediakan sari kata dalam video. } \\
\text { - Keperluan untuk memasukkan sumber rujukan lain sebagai } \\
\text { bahan tambahan kepada sukatan pelajaran semasa. } \\
\text { - Pertukaran daripada format PDF kepada format GIF untuk } \\
\text { mempercepatkan proses penggunaan e-buku. }\end{array}$ \\
\hline 7 & $\begin{array}{l}\text { KANDUNGAN SUKATAN PELAJARAN } \\
\text { - Keperluan penyelarasan kandungan dalam laman dengan } \\
\text { sukatan pelajaran bahasa Arab yang disediakan oleh } \\
\text { Kementerian Pelajaran Malaysia. } \\
\text { - Kesuaian kandungan dengan tahap penguasaan kanak- } \\
\text { kanak dan dilanjutkan kepada pringkat dewasa. } \\
\text { - Cadangan pembinaan prototaip bagi kegunaan para pelajar } \\
\text { peringkat sekolah menengah. } \\
\text { - Tahap kandungan mesti sesuai dengan tahap umur kanak- } \\
\text { kanak daripada darjah } 1 \text { hingga darjah } 6 \text {. } \\
\text { - Usaha ini boleh diteruskan melalui jalinan kerjasama } \\
\text { dengan Bahagian Pembangunan Kurikulum, Kementerian } \\
\text { Pelajaran Malaysia. }\end{array}$ \\
\hline
\end{tabular}




\subsection{KESIMPULAN}

Berdasarkan dapatan yang telah dihuraikan di atas, kajian ini mendapati bahawa laman EZ-Arabic yang telah dibangunkan dan diuji terhadap pengguna menggunakan Facebook ${ }^{\circledR}$ mempunyai kelebihan, kekurangan dan potensi untuk terus ditambahbaik pada masa hadapan. Walaupun dapatan yang dikumpul lebih bersifat kualitatif, para pengkaji mendapati bahawa dapatan secara kualitatif ini telah memberikan maklum balas terhadap laman EZArabic dengan lebih mendalam dan terfokus kepada aspek-aspek yang perlu ditambah baik seperti yang tertera dalam jadual 2.0.

Laman prototaip EZ-Arabic ini juga telah memenangi pingat gangsa dalam IIUM Research, Invention and Innovation Exhibition (IRIIE) 2012 anjuran Universiti Islam Antarabangsa Malaysia (UIAM) pada 21-22 Februari 2012 bertempat di Cultural Activity Centre (CAC), UIAM.

\section{Rujukan}

Abd. Rahman Daud. 2000. Faktor-faktor yang Mempengaruhi Penggunaan Alat Teknologi Pendidikan (ATP) dalam Pengajaran Matematik di Kalangan Guru Sekolah Rendah. Proceedings of the International Conference on Teaching and Learning: Strategising Teaching and Learning in the 21st Century. 2: 772-784.

Ashinida Aladdin, Afendi Hamat \& Mohd. Shabri Yusof. 2004. Penggunaan PBBK (Pembelajaran Bahasa Berbantukan Komputer) dalam Pengajaran dan Pembelajaran Bahasa Arab Sebagai Bahasa Asing: Satu Tinjauan Awal. GEMA Online Journal of Language Studies. 4(1).

Bruner, J. 1996. The Culture of Education. Massachusetts: Harvard University Press.

Bush, M. D. 2007. Facilitating the Integration of Culture and Vocabulary Learning: The Categorization and Use of Pictures in the Classroom. Foreign Language Annals. Winter. ProQuest Education Journals. 40: 4727-745.

Ellis, R. 1994. The Study of Second Language Acquisition. Oxford: Oxford University Press.

Ellison, N. B., Steinfield, C., \& Lampe, C. 2007. The Benefits of Facebook "Friends": Social Capital and College Students' Use of Online Social Network Sites. Journal of Computer-Mediated Communication. 12(4): article 1. http://jcmc.indiana.edu/vol12/issue4/ellison.html [10 Oktober 2012].

Gardner, R. C. 1985. Social Psychological Aspects of Language Learning: The Role of Attitudes And Motivation. London: Edward Arnold.
Gill, D. 2006. Effects of Technology on Second Language Learning. Journal of College Teaching \& Learning. 3(2): Feb 2006, 19-28, http://www.cluteinstitute-onlinejournals.com/PDFs/200651.pdf [20 November 2008].

Joliffe, A., Ritter, J. \& Stevens, D. 2001. The Online Learning Handbook, Developing and Using Web-Based Learning. London, UK: Kogan Page Limited.

Mayer, R. E. 2001. Multimedia Learning. $9^{\text {th }}$ edition. New York: Cambridge University Press.

Mohd Feham Md. Ghalib. 2006. The Design, Development and Testing on the Efficacy of a Pedagogical Agent on the Performance and Program Rating Scores Among Students Learning Arabic. Tesis Ph.D belum terbit, Universiti Sains Malaysia.

Mohd Feham Md. Ghalib \& Isarji Sarudin. 2000. On-line Arabic: Challenges, Limitations and Recommendations. National Conference on Teaching and Learning in Higher Education, Universiti Utara Malaysia.

Muhammad Sabri Sahrir \& Ghazali Yusri. 2012. Online vocabulary games for teaching and learning Arabic. GEMA Online ${ }^{T M}$ Journal of Language Studies. 12(3): 961-977.

Muhammad Sabri Sahrir, Mohd Firdaus Yahaya \& Mohd Shahrizal Nasir. 2012. EZ-Arabic for Children: A Virtual Learning Resource Tool For Malaysian Primary Schools. In: 6th International Conference on University Learning and Teaching, 20-21 November 2012, Concorde Hotel Shah Alam, Selangor.

Pimentel, J. R. 1999. Design of Net-Learning Systems Based on Experiential Learning. Journal of Asynchronous Learning Networks. 3(2): 64-90. Retrieved June 11, 2002, from $\mathrm{http}: / /$ www.aln.org/publications/jaln/v3n2/v3n2_pimentel.asp.

Salsbury, D. E. 2006. Comparing teacher-directed and computer-assisted instruction of elementary geographic place vocabulary. The Journal of Geography. 105(4): Jul/Aug 2006, ProQuest Education Journals.

Sharifah Sofiah, S. Z., Siti Zobidah Omar, Jusang Bolong and Mohd. Nizam. 2011. Facebook Addiction Among Female University Students. Revista de Administratie Publica Si Politici Sociale. 2(7): 95-109.

Siti Fatimah Ahmad \& Ab. Halim Tamuri. 2010. Persepsi Guru Terhadap Penggunaan Bahan Bantu Mengajar Berasaskan Teknologi Multimedia dalam Pengajaran j-QAF. Journal of Islamic and Arabic Education. 2(2): $53-63$

Tripp, S. \& Bichelmeyer, B. 1990. Rapid Prototyping: An Alternative Instructional Design Strategy. Educational Technology Research \& Development. 38(1): 31-44.

Zawawi Ismail. 2008. Penilaian pelaksanaan kurikulum kemahiran bertutur Bahasa Arab Komunikasi di Sekolah Menengah Kebangsaan Agama. Tesis Ph.D belum terbit, Universiti Kebangsaan Malaysia. 